\title{
A METHOD FOR DELIMBING TREE-TRUNKS AND A DEVICE FOR APPLYING THE METHOD
}

\author{
Konstantin Rukomojnikov* Sergei Vedernikov Marsel Gabdrahmanov \\ Volga State University of Technology, Yoshkar-Ola, Russia
}

The article is devoted to the improvement of the quality of tree-trunks delimbing by means of time-effective bringing the delimbing knife into an operating position before its contact with the branches. The set goal was achieved by bringing the delimbing knife into the operational mode, parallel to the direction of the tree-trunk feed motion, following the load shift of the pusher beyond the cutting edge. This type of load emerges when the branches press upon the pusher. After the stress is finished both mechanisms return to their original position. The described method and the construction of the mechanism provides placement of the delimbing knife in the operational position, thus enhancing the delimbing quality.

Key words: Forestry machinery, Harvester head, Dissipative forces, Delimbing knives, Tree

\section{INTRODUCTION AND LITERATURE REVIEW}

Over the past decade the forestry machinery pool has significantly expanded and became diverse all over the world. An ever-increasing requirements of this equipment force manufacturers to constantly improve the forestry machinery.

One of the most promising and intensively developing technological processes of timber harvesting are the technological processes which use state-of-the-art harvesting machinery capable to remove branches from the tree-trunks on the logging site [01]. Harvesters and processors may be considered as this type of machinery. A shift of harvesting enterprises to progressive logging technologies ensures enhancing the productivity, improving the quality of the logging site processing and minimizing negative environmental impact.

Summing up the aforesaid, it is worthwhile to note that modernization of harvester and processor technological equipment is important and has a valuable scientific and practical value.

Many researchers [02, 03, 05] are involved in searching solutions to improve the structure of the working elements of delimbing and processing machines. Based on the functional and technological analysis of harvester head, P.V. Budnik [04] and A.V. Demchuk [01] devise a development matrix, which contains all possible ways for its improvement. Among other ways of efficiency enhancement of the harvester head operation we consider it to be necessary to reduce the impact of dissipative forces emerging during trunk feeding process.

A harvester head features movable delimbing knives mounted on both sides of the mechanism. They also fulfill the gripping function.

A fixed delimbing knife is mounted at the front of the frame construction of the harvesting device in order to improve the performance of delimbing knives. The fixed knife is used to remove branches from the tree trunk in- accessible by the movable delimbing gripping knives. This method of delimbing and the construction of the head are presented in patents US $6318425 \mathrm{~B} 1$ and US $5785101 \mathrm{~A}$, both of them use a fixed delimbing knife rigidly mounted on the frame structure.

A significant drawback of this method and the construction is a high probability of damaging the tree-trunk by the delimbing knife blade. Additionally, it requires more energy to process the tree and damages the tree-trunk when its form is not even enough. The form of tree trunk in hardwood species like oak, beech and walnut can vary in comparison with other tree species. It is undesirable for the delimbing knife edge to damage the tree-trunk because of its curvature form. In some tree species the lower part of the trunk is free from branches, which makes it unnecessary to use delimbing knives. In most cases it is necessary to remove branches only from the upper part of a tree. Thus, a delimbing knife may be either fixed or movable, and slide along the rough surface of the tree-trunk. Sample delimbing knives are presented in US $4194542 \mathrm{~A}$ and US $5732754 \mathrm{~A}$.

According to the previous level a tilting blade is used. The cutting edge of this blade can be moved further from the tree-trunk in comparison with its usual position. At present, the most similar to the suggested technical solution is the delimbing method described in patent US 2513415 C2 according to which feeding mechanisms feeds a treetrunk in the longitudinal direction through the ring formed by the grabbing delimbing knives. The rotation axes of these knives necessary for grabbing the stem are parallel to the aforesaid longitudinal direction and perpendicular to the axes of rotation. In this way, they may be adjusted to proper position, i.e. operate in such a way, that in the working mode the delimbing knives are allocated parallel to the stem feed. Provided there is no external stress at the moment, when the knives are in a standby mode, they may tilted relative the above said transverse axes of rotation. 
The structure of the delimbing mechanism described above used to implement this method features feeding wheels for longitudinal feed of the processed tree-trunks along the frame. The construction includes a delimbing knife and tilting and controlling mechanism to adjust the position of the delimbing knife. At no external stress from the removal of branches the delimbing knife is inclined to the direction of the tree-trunk feed motion. Under the stress occurring as a result of removal of branches, the delimbing knife can be set in the position parallel to the tree-trunk feed.

The technical solution described above does not sufficiently take into consideration the inclination of branches and the form of their base in some tree species, which represents a significant drawback of this method and the whole construction.

\section{MATERIALS AND METHODS}

During delimbing the blade is exposed to a high pressure. In order to implement this process the knife construction must be durable and reliable. Moreover, the moving agent of the delimbing knife must be insensitive to beating and be water and dust proof. At the same time a delimbing blade must be available at any moment when it is necessary, as the tree-trunk features branches that must be removed even with the surface.

The present invention aims to improve the quality of delimbing tree-trunks by means of time-effective bringing the delimbing knife into an operating position before its contact with the branches.

The set goal was achieved by bringing the delimbing knife into the operational mode, parallel to the direction of the tree-trunk feed motion, following the load shift of the pusher beyond the cutting edge. This type of load emerges when the branches press upon the pusher. After the stress is finished both mechanisms return to their original position.

The key characteristic of the aforementioned delimbing mechanism is the fact that the upper edge of the delimbing knife features outpouching tongues fitting into the grooves of the guide fixed on the frame construction of the delimbing device parallel to the tree feed. Inside this feeder there is a pusher with reciprocating motion. The front part of the pusher follows the shape of the delimbing knife blade. In the absence of the external pressure it is located in front of the delimbing knife blade. Under the pressure the pusher slides along the frame (guide) which is followed by pressing the pusher tongues and placing the delimbing knife in the operational position. When the pressure ends, pusher turns back in the front, tongues are back in grooves and the delimbing knife is in the original position.

Figure 1 presents a general view of the device with the developed delimbing mechanism. Figure 2 presents a general view of the delimbing mechanism in the position before the branch removal. Figure 3 presents the general view of the delimbing mechanism under the pressure created by branch, during the branch removal. Figure 4 presents a technical drawing of the delimbing mechanism in section in non-operating position before the branch removal. Figure 5 presents a technical drawing of the delimbing mechanism under pressure occurring as a result of branch removal, the operating position of the delimbing knife is parallel to the direction of the feed motion.

The device is attached to the manipulator of a harvester and consists of the frame with rolls (1) for longitudinal feed of the processed trunks (2) along the frame, (3) movable and (4) nominally fixed delimbing knives, axes (5) for titling movable delimbing knives.

\section{RESULTS}

The delimbing mechanism used to remove branches from the side of the tree-trunk pressed upon the frame of the device consists of a fixed delimbing knife 4 implemented in the form of 6 tilting and controlling mechanism of the position of the aforesaid delimbing knife 4; a transverse titling axis 7 for the inclination of the delimbing knife; a guide 8 rigidly fixed on the frame of the delimbing device parallel to the direction of the trunk motion, pusher 9 , a mechanism of reciprocator motion of a pusher inside the guide occurring due to delimbing load change 10, in the form of a spring 11. The pusher is installed in such a way that it can freely move inside the guide, which results in pressing the tongue 12 located on the rear side of the delimbing knife and turning the delimbing knife into the position parallel to the direction of feed motion.

The pusher construction has a groove 13 in the form of non-right triangle with a major (longer) cathetus lying on the same plane as the pusher and a right angle in the rear part. In terms of its form and size the tongue is compatible with the forms and size of a groove, or otherwise it can have an arc-shaped top surface. On the frame of the mechanism there is a limiting element. A delimbing device features a stop 15.

The device equipped with a delimbing mechanism operates as follows.

The tree-trunk is grasped by the feed rollers and embraced by the delimbing knives. The knives form a ring. The drive rollers help feed the tree-trunk though the delimbing knives in the longitudinal direction. At no external stress and non-operational position in order to avoid unnecessary damages of the tree-trunk the nominally fixed delimbing knife driven by the springs of the tilting mechanism controlling its position is tilted relative to the transverse axis of rotation by angle $\beta$ so that its blade edge is removed from the trunk as far as possible. Thus, the outpouching tongue is inside the pusher groove. In order to implement this method it is also possible to use a device in which several delimbing knives can be turned relative to their transverse axes of rotation (not shown in figures). By removing the delimbing knife away from the trunk, the knife moves along without plunging into irregularities on the surface. 


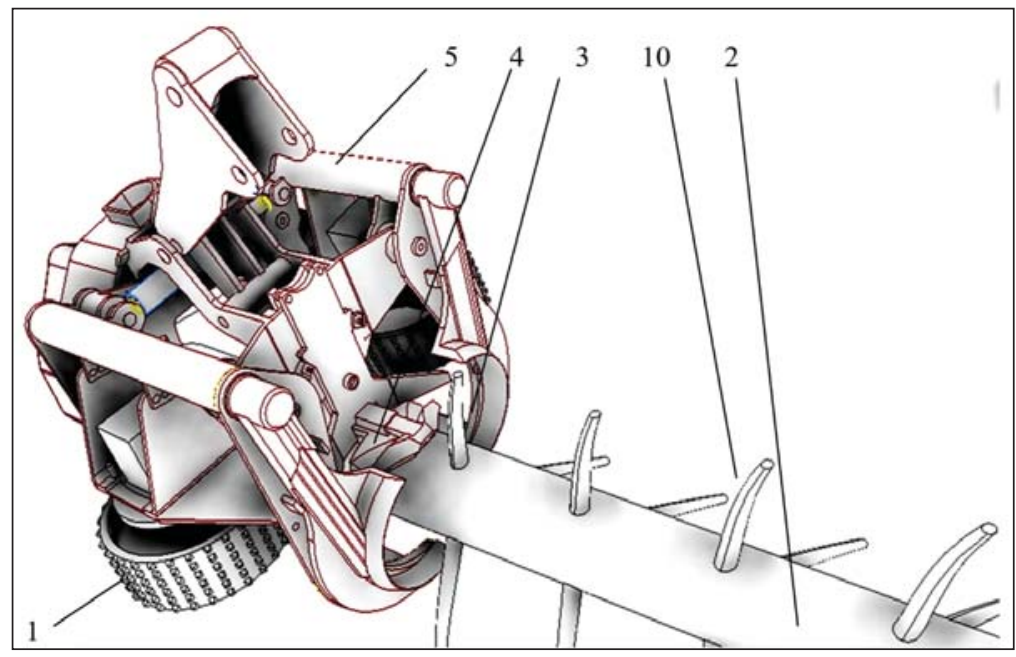

Figure 1: General view of the device with the developed delimbing mechanism

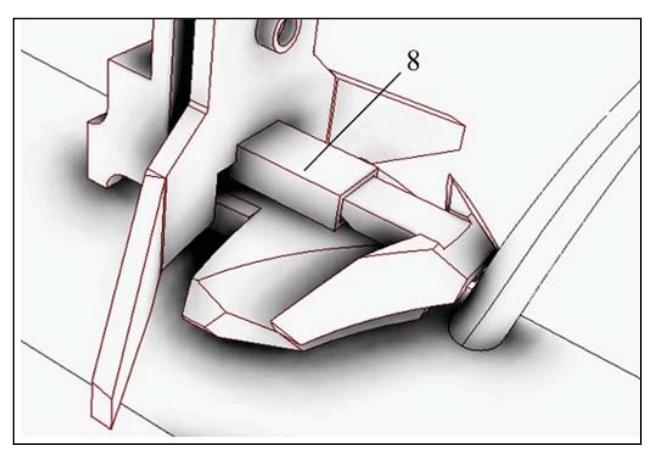

Figure 2: General view of the delimbing mechanism in the position before the branch removal

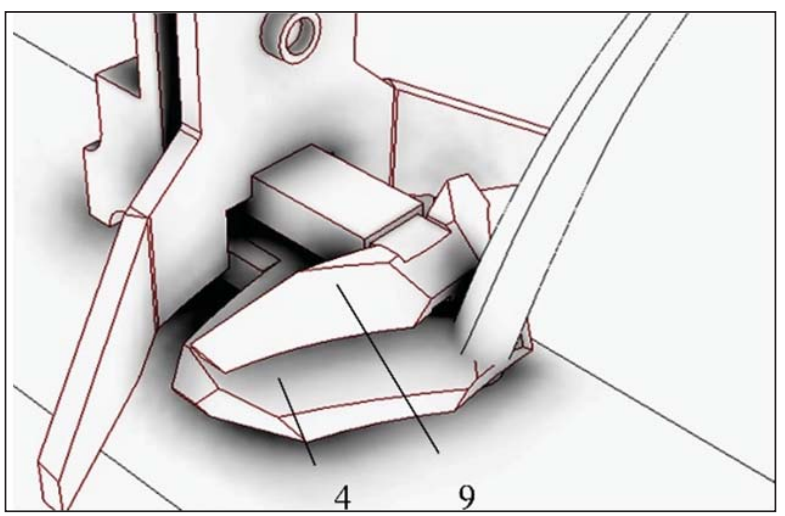

Figure 3: The general view of the delimbing mechanism under the pressure created by branch, during the branch removal

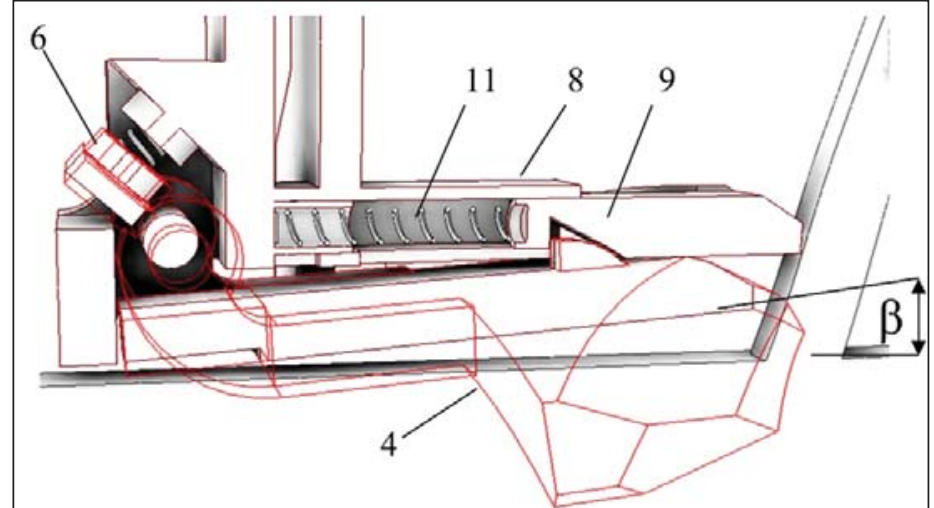

Figure 4: Technical drawing of the delimbing mechanism in section in non-operating position before the branch removal

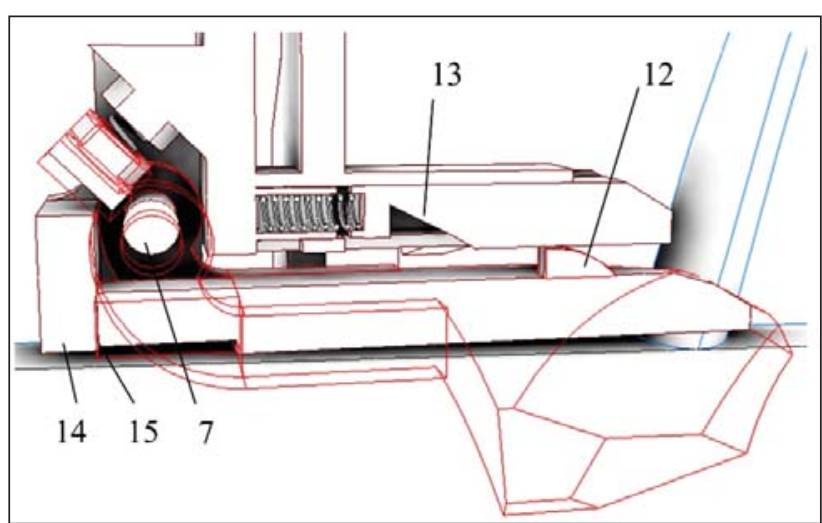

Figure 5: Technical drawing of the delimbing mechanism in section under stress occurring as a result of branch removal, the operating position of the delimbing knife is parallel to the direction of the feed motion 
Such position of the delimbing blade can be used to process all the tree species particularly those with uneven tree-trunk surface or tree bases free from branches.

At the moment of contact with the branch it is the pusher driven by the reciprocator motion mechanism inside the frame that slides inside towards the frame. Thus, the tongue of the delimbing knife is under stress. It slides inside the groove within the pusher construction, thus moving along its inclined plane and brings the delimbing knife into motion, which turns relative to the transverse axis into the operation position parallel to the direction of the stem feed motion. In the process of motion the pusher goes beyond the cutting edge of a delimbing knife, which when contacting with a branch delimbs it flush with the stem surface. In order to ensure structural reliability of the construction in the operational position of a delimbing knife, the stop mounted in the rear panel comes into contact with the limiter allocated on the case, thus preventing its further movement caused by the pressure of the removed branch. The surface of the limiter takes the load of the delimber knife.

After the branch is removed and the load arising from the contact with the branch stops, driven by the mechanism of the reciprocal motion the pusher shifts inside the guide away from the mechanism case. At the moment when the positions of a tongue and a groove driven by the tilting and controlling mechanism, the knife is transferred into non-operational position. The tongue comes into a groove of a pusher by sliding along the inclined plane of a groove and prevents the further movement of a pusher along the guide. Thus, all the aforesaid mechanisms return to the original non-operating position. The mechanism resumes its work when it comes into contact with the next branch.

The described method and the construction of the mechanism allow to move the delimbing knife in the operational position, thus enhancing the delimbing quality.

\section{ACKNOWLEDGEMENT}

The research was conducted with the financial support from the 000 Martreyd, (a limited liability company under the laws of Russian Federation) in the frames of the scientific and research project №06.522/18.

\section{REFERENCES}

1. A.V. Demchuk. (2012) Modernization of the technological equipment of harvester for improving the efficiency of delivery of logs. Engineering Bulletin of Don. Volume: 20. № 2: 542-546.

2. F.V.Poharnikov, Yudina N.Y., Bulanov A.S.,. Ladentsov P.G. (2012) Analysis of the state of the technical equipment of the forest process industry. Lesotechnic journal, № 2:100-105.

3. P.M.Mazurkin. (1990) Search design of forestry equipment: Study Guide - Saransk: publishing house of the University of Saratov: 304.

4. P.V. Budnik. (2012) Functional-technological analysis of harvesteral head. Science and business: ways of development. 9 (15): 036-038.

5. V.S. Syunyov, A.A Seliverstov. (2005) Working bodies of harvesters.: designing and calculation. Monograph/ Petrozavodsk: Feder. Education Agency, Gos. educated. institution of higher education. prof. education Petrozav. state. un-t: 204. 